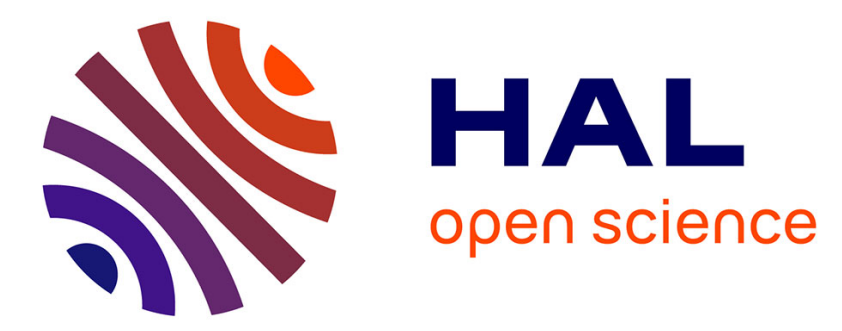

\title{
ANALYSIS OF PERMANENT RESISTIVE STATES CREATED BY LIGHT PULSES IN SUPERCONDUCTING FILMS
}

\author{
R. Buisson, R. Chicault, F. Madeore, R. Romestain
}

\section{- To cite this version:}

R. Buisson, R. Chicault, F. Madeore, R. Romestain. ANALYSIS OF PERMANENT RESISTIVE STATES CREATED BY LIGHT PULSES IN SUPERCONDUCTING FILMS. Journal de Physique Colloques, 1978, 39 (C6), pp.C6-509-C6-510. 10.1051/jphyscol:19786227 • jpa-00217648

\section{HAL Id: jpa-00217648 https://hal.science/jpa-00217648}

Submitted on 1 Jan 1978

HAL is a multi-disciplinary open access archive for the deposit and dissemination of scientific research documents, whether they are published or not. The documents may come from teaching and research institutions in France or abroad, or from public or private research centers.
L'archive ouverte pluridisciplinaire HAL, est destinée au dépôt et à la diffusion de documents scientifiques de niveau recherche, publiés ou non, émanant des établissements d'enseignement et de recherche français ou étrangers, des laboratoires publics ou privés. 


\title{
ANALYSIS OF PERMANENT RESISTIVE STATES CREATED BY LIGHT PULSES IN SUPERCONDUCTING FILMS
}

R. Buisson, R. Chicault, F. Madeore and R. Romestain

Laboratoire de Spectrométrie Physique, Université Scientifique et Médicale de Grenoble, B.P. 53, 38041, Grenoble Cedex, France

\begin{abstract}
Résumé.- Les états résistifs permanents créēs dans des films supraconducteurs, soit par une impulsion lumineuse, soit par réduction rapide du courant dans le film, sont analysés expérimentalement. Leur comportement pour une faible variation du courant est décrit et la preuve est donnée qu'ils ne résultent pas simplement d'effets thermiques.
\end{abstract}

Abstract.- Permanent resistive states in superconducting films created either by a 1 ight pulse, or by fst decrease of the electrical current in the film are analysed experimentally. Their behaviour under small variation of the current is described and the proof is given that they are not due to purely heating effects.

The study of off equilibrium states in superconducting films, created either by injection of quasiparticules or by laser pulses, has recently been very active /1/. Most of the time, the off equilibrium state disappear with the perturbation. We recently reported on the observation of metastable resistive states created, at $\mathrm{T}<\mathrm{T}_{\mathrm{c}}$, by laser or electrical pulses. Here we further describe some experiments in order to analyse the nature of these resistive states.

Our experiments are made on pure Al films, 400 to $800 \mathrm{~A}$ thick, (for which $\mathrm{T}_{\mathrm{c}} \sim 1.25 \mathrm{~K}$ ), their geometry is sketched in the inset of figure 1. Analogous results (apart from the well pronounced steps of Fig. 2) have been obtained on linear films.

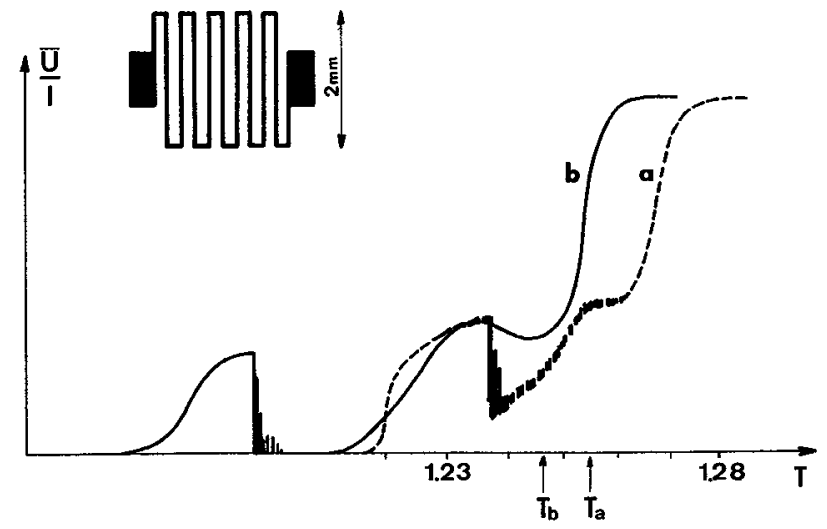

Fig. 1.- Variation of $\bar{R}=\frac{\bar{U}}{\mathrm{~T}}$ versus temperature for a typical film with light pulses and for : a) $I=100 \mu \mathrm{A}$, b) $I=150 \mu \mathrm{A}$. $T_{a}$ and $T_{b}$ are the temperatures for which the current used is the lowest critical current ( $I_{C_{1}}$ of Fig. 2). The inset shows the shape of some films used.
Figure 1 shows the variation of the average resistance $\bar{R}=\frac{\bar{U}}{I}$ versus the helium bath temperature, for a film irradiated by laser pulses 6 ns long with a periodicity of $0.1 \mathrm{~s}$. As described in reference $/ 2 /$, resistive states created below $\mathrm{T}_{\mathrm{c}}$ are stable.

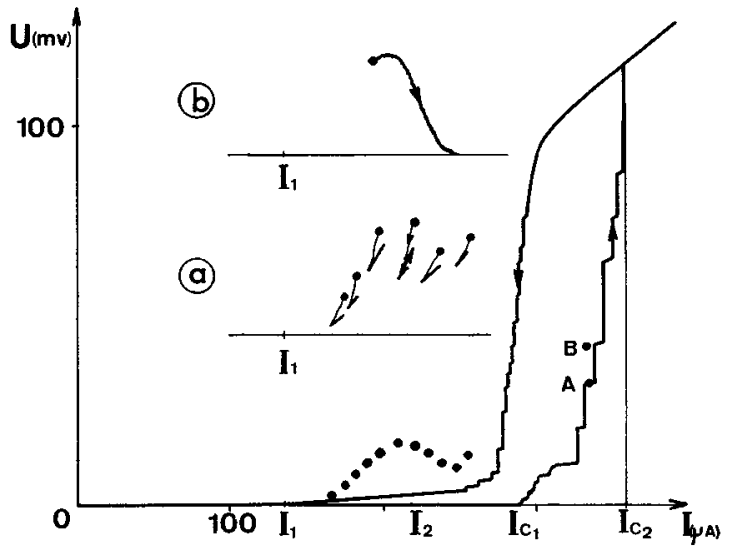

Fig. 2 .- Solid line : U - I characteristic of a typical film for $\mathrm{T} \sim 1.2 \mathrm{~K}<\mathrm{T}_{\mathrm{c}}$. Dots represent the resistive states created by 1 ight pulses at constant current. Inset a) shows the evolution of some of these states under a small sweep of $I$. Inset b) shows the evolution under a larger increase of the current. The U scale for the insets is twice that of the characteristic.

Figure 2 shows a typical characteristic U - I at $\mathrm{T} \stackrel{\sim}{<} \mathrm{T}_{\mathrm{c}}$ obtained with a triangular wave form current whose frequency is lower than $1 \mathrm{kHz}$. Steps observed on the rising part of the waveform correspond to resistive states with ohmic characteristic. Using an optical imaging set-up we can reduce the illumination to a circular surface whose diameter is close to the widht of a branch of the film. For 
a given value of the intensity in the film, a weak enough laser pulse triggers the jump towards another resistive state ( $\rightarrow B$ on Fig. 2 for instance) only if the illuminated branch has not yet become normal. A complete analysis has let us conclude that the steps correspond to film states for which only a certain number of branch have transited to the normal state, the order in which these transitions happen when increasing $I$, is always the same for a given experiment. However this order is modified when soldering or gluing new wires to the film. The transition of one branch as a whole is we11 understood in the frame of the hot spot model proposed by Skocpol et al. /3/ : the first normal point is created either by going over the critical current at a defect in the film or the substrate or by a light pulse. We were able to follow the propagation of the normal state which turns out to be rather long, of the order of $40 \mu \mathrm{s}$. Nonetheless it is difficult to understand such a large spread in the $I_{c}$ values (ranging from $I_{c_{1}}$ to $I_{c_{2}}$ ) for different branches as well such an independence of the branches.

Points in figure 2 shows metastable resistive states created at given $T$ and $I$, by a laser or electrical pulse $/ 2 /$. In the inset $2 a$, is sketched the dynamical characteristic of such states, obtained by a small amplitude sweeps of the electrical current $I$. It is obvious that the state following the pulse is not completely stable with respect to a variation of the current. However after a few sweeps one reaches a stable characteristic : it is to be emphasized that this characteristic is not ohmic. Moreover it depends on the amplitude of the sweep, when this one is too large, the film resistance can get back to almost zero value (see inset $2 \mathrm{~b}$ ). Such a behaviour, as evidenced by figure $2 b$, seems a direct proof that the resistive state is not due to a simple thermal effect since the increase of $I$, and consequently of the heat generated by Joule effect, can bring the film back to a lower resistance state.

Finally, let us mention three more observations

i) It is impossible to get permanent resistive states for $I$ smaller than $I_{1}$, characterizing the end of the hysteresis curve (Fig. 2).

ii) After a slow variation of the current from 0 to a value larger than $I_{c \hat{2}}$, and back down to the value $\mathrm{I}_{2}$ (Fig. 2) an increase of I leads the characteristic to almost follow the decreasing part of the hysteresis curve; on the other hand when the current is allowed to get smaller than $I$, then the film gets back to the superconducting state and on increasing I the usual characteristic is followed.

iii) The appearance on the decreasing part of the characteristic (Fig. 2) of small segments representing non-ohmic states. The resistive states created by laser or leectrical pulses could have the same nature as those obtained on the decreasing part of a slow hysteresis cycle. They are certainly analogous to the phase slip centers proposed by Skocpol et a1. $/ 4 /$ and recently analysed by Dolan and Jacke1/5/.

\section{References}

/1/ See for instance, among others : Sai-Halasz, G.A., Chi, C.C., Denenstein, A. and Langenberg, D.N., Phys. Rev. Lett. 33 (1974) 215 ; Golovaskhin, A.I., Mitsen, K.V. and Motulevich, G.P., Sov. Phys. J.E.T.P. 41 (1975) 701 ; Dynes, R.C., Narayananiurti, V. and Garno, J.P. Phys. Rev. Lett. 39 (1977) 225

/2/ Buisson, R., Chicault, R., Madeore, F. and Romestain, R., J. Physique Lett. (à paraître)

/3/ Skocpol, W.J., Beasley, M.R. and Tinkham, M., J. App1. Phys. 45 (1974) 4054

/4/ Skocpol, W.J., Beasley, M.R. and Tinkham, M., J. Low Temp. Phys. 16 (1974) 145

/5/ Dolan, G.J. and Jackel, L.D., Phys. Rev. Lett. 39 (1977) 1628 